\title{
Campanha de Pé no Chão Também se Aprende a Ler. Entrevista com Moacyr de Góes
}

Neste ano de 2015, no Rio Grande do Norte, instituições de direitos humanos, culturais e educacionais organizaram homenagens, seminários e audiências públicas pelos cem anos de nascimento de Djalma Maranhão (1915-2015) e divulgaram um cartaz comemorativo - Três Dimensões de Djalma Maranhão: Política, Educação e Cultura. Especialmente no governo municipal de Dialma Maranhão (1960-1964), o Secretário de Educação de Natal, Moacyr de Góes, professor, educador e intelectual comprometido com os problemas humanos e sociais do seu tempo, planejou, coordenou e dinamizou a Campanha de Pé no Chão Também se Aprende a Ler, reconhecida como um Movimento de Educação Popular e de construção de uma Escola democrática. Por tudo que representou esse Movimento de Educação Popular e a Experiência da Campanha de Pé no Chão Também se Aprende a Ler para a construção das bases teóricas de uma Escola democrática, o Conselho Editorial da Revista Educação em Questão decidiu republicar a entrevista de Moacyr de Góes nesta edição da Revista Educação em Questão.

Marta Maria de Araújo Editora Responsável da Revista Educação em Questão

No dia 27 de março de 2008, faleceu, no Rio de Janeiro, o professor, o educador e o principal artífice da Campanha de Pé no Chão Também se Aprende a Ler, Moacyr de Góes. O professor Willington Germano, por ocasião do falecimento desse grande intelectual assim se expressou: Moacyr de Góes foi um organizador da cultura no melhor sentido da palavra. Intelectual comprometido com os problemas do seu tempo, fez do seu mister de professor e educador uma luta persistente por justiça social para um mundo melhor. Por tudo o que representa para a história da educação no Rio Grande do Norte e no Brasil, o Conselho Editorial da Revista Educação em Questão decidiu pela republicação de sua entrevista inserida na Revista Educação em Questão, Natal, v. 21, n. 7, set./dez. 2004. 


\section{A Campanha "De Pé no Chão Também se Aprende a Ler" pode ainda ser referência para outras experiências educacionais democráticas?}

Moacyr de Góes: De início quero trazer uma notícia ainda inédita e que qualifica o tema que nos congrega: "De Pé no Chão Também se Aprende a Ler," 43 anos depois. Informo às companheiras e companheiros do Rio Grande do Norte que o grupo de trabalho que está hoje em Timor Leste, (re)construindo o sistema de educação daquele bravo povo, elegeu o "De Pé no Chão Também se Aprender a Ler," como a melhor experiência brasileira para se adequar à realidade de pobreza e devastação de guerra daquele país. Faz quatro anos que fui procurado por representante desse grupo de brasileiros que já seguiu para o Timor Leste e tive a oportunidade de oferecer a bibliografia possivel para embasar os trabalhos educativos que lá serão desenvolvidos, passando, evidentemente, pelo crivo da realidade local, uma vez que todos estão cientes que modelo de educação não se exporta. Nesta oportunidade não posso deixar de registrar uma visão profética de Dialma Maranhão quando, ao escrever, no exílio, seu texto sobre a Campanha "De Pé no Chão Também se Aprende a Ler," editado pela Prefeitura de Natal (1999) dizia: "Da mesma maneira que um exército na guerra clássica não pode adotar técnica guerrilheira, nosso método não serve para países adiantados, para nações que alcançaram a etapa superior da industrialização. De Pé no Chão Também se Aprende a Ler" é uma experiência válida para as áreas do mundo subdesenvolvido. "Pé no Chão" para usar uma expressão em moda foi uma guerrilha de alfabetização e cultura contra o poderoso Império da lgnorância." Esta concepção político-educacional do Prefeito Dialma Maranhão está a se confirmar, agora, nas lutas de reconstrução do Timor Leste e é bom saber que a proposta educacional de nossa Cidade do Natal não foi destruída pelo Golpe de 1964, pois, 40 anos depois, ela ressurge num estado do Oriente de língua portuguesa. Sem triunfalismo, mas confortado pela História, compartilho essa notícia com a Universidade do Rio Grande do Norte, instituição que através de suas lideranças estudantis e de alguns professores esteve presente ao esforço da Prefeitura de Natal, de novembro de 1960 a abril de 1964, em erradicar o analfabetismo e construir uma política de educação e de cultura com as classes subordinadas. 


\section{Fala-nos do contexto político em que foi concebida a Campanha "De Pé no Chão Também se Aprende a Ler" em Natal.}

Moacyr de Góes: Como dizem os documentários de cinema: estamos em Natal, em 1960. Dois anos antes, a Frente do Recife, aliando comunistas, socialistas, nacionalistas, cristãos e liberais havia elegido Miguel Arraes Prefeito do Recife. Aqui, em Natal, Dialma Maranhão, em 1960, costurava alianças semelhantes. A década de 1960 começava pelo avanço democrático da primeira eleição para prefeito de Natal e dava eco às esperanças de mudanças no mundo, com a Revolução Cubana e a convocação do Concílio Vaticano II, sob a égide de João XXIII. No Brasil, o desenvolvimentismo capitalista acenava para uma aceleração histórica de construção de cinquenta anos em cinco. Um grupo industrial assumia a hegemonia do poder; o nacionalismo denunciava a remessa de lucros para exterior das empresas estrangeiras; o sindicalismo operário ganhava uma face mais nítida; e o latifúndio era questionado no campo. No Nordeste, a SUDENE, de Celso Furtado, abria caminhos de esperança. No Recife, o Movimento de Cultura Popular (MCP) trabalhava uma linha contra-hegemônica no campo da educação tradicional. Com esse caldo de

244 cultura, assumindo uma posição nacionalista de esquerda, Dialma Maranhão liderava a mobilização popular em Natal.

\section{Explique-nos a organização popular em Natal, sob a liderança de Djalma Maranhão.}

Moacyr de Góes: Com os Comitês Nacionalistas, Dialma Maranhão passou da mobilização para a organização popular. $\bigcirc$ que é um Comitê Nacionalista? É o agrupamento de homens e mulheres, em número variável, desburocratizado, que recebe em uma casa comum de qualquer rua, Dialma Maranhão e colaboradores, com eles discutem os problemas do bairro e da cidade. Essas discussões levam à necessidade de organização de núcleos dispostos a reivindicar, trabalhar e ganhar as eleições de 3 de outubro de 1960. Segundo Willington Germano, numa população de 154.276 habitantes, 240 Comitês Nacionalistas foram organizados em Natal. Numa fase mais avançada de organização criou-se um calendário de convenções dos Comitês por bairros quando são discutidas e aprovadas as listagens de problemas e soluções devidamente priorizadas. Finalmente, nos dias 6 e 7 de setembro de 1960, na 
sede do Alecrim Clube, com a participação de mais de 200 Comitês, além de delegados do interior do Estado, foi realizada a I Convenção Estadual do Movimento Nacionalista. O temário do encontro, transcrito por Willington Germano, dá ideia da abrangência das discussões quando foram homologadas as candidaturas de Lott-Jango (Presidência da República), AluizioAlves e Walfredo Gurgel (governo do Estado), Dialma Maranhão e Luiz Gonzaga dos Santos (prefeitura de Natal).

\section{A priorização da educação escolar e da cultura no governo Djalma Maranhão foi resultado da I Convenção Estadual do Movimento Nacionalista?}

Moacyr de Góes: Da consolidação das propostas aprovadas nas convenções de bairro dos Comitês Nacionalistas emergiram a educação e a cultura como meta número um, além da erradicação do analfabetismo. Esta decisão era resultado da constatação que a população de Natal, desde a II Guerra Mundial, crescera multiplicada por quatro e a oferta de matrículas no ensino público fundamental diminuíra. À época, a Secretaria Municipal de Educação com cerca de um ano de fundação ainda engatinhava. Assim, com a I Convenção Estadual do Movimento Nacionalista, estava pronto o programa administrativo do próximo prefeito de Natal. Caberia a Djalma Maranhão executá-lo, a partir da posse de 5 de novembro de 1960.

\section{Quais as primeiras medidas da Secretaria Municipal de Educação, sob sua direção política?}

Moacyr de Góes: Dialma Maranhão, Prefeito de Natal, começou então uma longa jornada de organização na Secretaria Municipal de Educação (SME), para a qual eu fui designado. Criou-se um Grupo de Trabalho de Educação Popular, integrado por professores e estudantes universitários, inclusive, o presidente do Diretório Central dos Estudantes (DCE) Ivis Bezerra. Na Diretoria de Ensino, Omar Pimenta, com grande dedicação, articulava e multiplicava a incipiente rede das chamadas Escolinhas (locais cedidos gratuitamente à Prefeitura para instalação das classes de alfabetização). Sem contar com um magistério qualificado, dada sua inexistência, partimos para a preparação de 
um professorado leigo através de um primeiro curso que reuniu mais de 200 participantes, ainda em 1960-1961. Aí vai surgir a figura excepcional de Margarida de Jesus Cortez, que organizou a Coordenação Pedagógica da SME, com grande competência e oferecia subsídios técnicos ao Grupo de Trabalho de Educação Popular. De março a junho de 1961, desenvolveu-se o I Seminário de Estudos dos Problemas de Educação e de Cultura do Município de Natal, envolvendo os intelectuais tradicionais da Cidade e procurando sensibilizá-los para a luta de erradicação do analfabetismo. Mas, ao lado do entusiasmo e otimismo do início do Governo de Dialma Maranhão, havia também angústia. É que estavam nas mãos do Prefeito e nas nossas, a responsabilidade de executar um Programa, para o qual o município não tinha recursos financeiros. Sabíamos o que fazer, mas não o como fazer.

\section{Como nasceu a original ideia da Campanha "De Pé no Chão Também se Aprende a Ler"?}

Moacyr de Góes: Trabalhávamos, mas a sensação era de darmos "murros" numa grande almofada: a marca do punho ficava impressa no algodão que se esgarçava para as bordas, ou que carregávamos água em peneira. Nesse momento, fui eu convocado pelo Comitê Nacionalista das Rocas, presidido pelo Presbítero José Fernandes Machado, para discutir, justamente, a erradicação do analfabetismo naquele Bairro. Levei para a reunião dois dados: a estatística do crescimento de Escolinhas nas Rocas e a notícia de que não havia dinheiro para construir a tão sonhada rede de escolas municipais. Longa foi à discussão e sincera a cobrança de compromissos da campanha eleitoral de Djalma Maranhão. Em meio à discussão, um participante pede a palavra a propõe: se não pode construir escolas de alvenaria faça escolas cobertas de palha de coqueiro, mas faça a escola. De todas as discussões políticas que participei na minha vida e não foram poucas estas foi uma oportunidade inesquecível pela criatividade da proposta e novas sugestões de desdobramentos. No final, na melhor tradição democrática, a proposta foi votada e aprovada pelo Comitê Nacionalista das Rocas. No mesmo dia levei a decisão ao Prefeito. Ele aprovou a ideia. E dois dias depois, com os marceneiros da Prefeitura, José Ribamar à frente, e a ajuda dos pescadores do Canto do Mangue, começou a ser erguido o primeiro Acampamento Escolar. Em fevereiro de 1961, de microfone à mão, acompanhado do Grupo de Trabalho 
de Educação Popular da SME, caminhando pelas areias das Rocas, Dialma Maranhão convocava o povo das Rocas para a matrícula nos Acampamentos Escolares. Estava nas ruas a luta pela erradicação do analfabetismo em Natal que, pouco depois, veio se chamar Campanha "De Pé no Chão Também se Aprende a Ler."

\section{Tendo como referência o Movimento de Cultura Popular (MCP) do Prefeito Miguel Arraes, qual foi o programa cultural e educativo do Governo Djalma Maranhão?}

Moacyr de Góes: $\bigcirc$ Programa Cultural do Governo Dialma Maranhão, a cargo da Diretoria de Documentação e Cultura (DDC), dirigida com grande competência por Mailde Pinto abrangia as praças de cultura; as bibliotecas populares; os círculos de leitura; os círculos de cultura de Paulo Freire; os programas radiofônicos diários; o teatro; o coral; os jograis; as edições de cartilha para adultos, a edição de literatura de cordel; a mobilização dos grupos de representação de autos populares, os cantos e danças folclóricas. $\bigcirc$ historiador e foclorista Câmara Cascudo presidindo mesas nacionais de discussão do folclore; Newton Navarro dirigindo exposições na Galeria de Arte; Caldas Moreira pesquisando, registrando, mobilizando na periferia da Cidade, a existência dos grupos folclóricos; a pesquisa educacional desenvolvida por Antônio Campos identificando e fazendo o perfil dos analfabetos; a iniciação ao trabalho dos cursos de "De Pé no Chão Também se Aprende uma Profissão"; Chico Santeiro ensinando sua arte aos meninos do Acampamento Escolar das Rocas; Omar Pimenta tocando a Federação Carnavalesca e organizando os desfiles de Momo; nas festas juninas e natalinas os fandangos, as cheganças, os bambelôs, os pastoris, os congos de calçola e os congos de saiotes, os bois calembas e a Sociedade Ararunas de Danças Antigas, sob a direção de impecável elegância de Mestre Cornélio; os Círculos de Pais e Professores da Campanha indo além da discussão de ensino e aprendizagem, para o debate da questão social: lembro que a luz e a água chegaram ao bairro Nordeste, à margem da ponte de lgapó, por mobilização e pressão política do Círculo de Paes e Professores de seu Acampamento Escolar; a educação para a produção com suas hortas e aviários nos Acampamentos e nestes, também, a recreação infantil como porta para o descobrimento da cultura popular; a SME editando um Boletim para documentar o desdobramento do trabalho; 
- Centro Popular de Cultura de Natal, ligado ao CPC da União Nacional dos Estudantes (UNE), sob a liderança de Hélio Vasconcelos, somando-se nos debates políticos junto aos sindicatos dos trabalhadores; a UFRN, através do Reitor Onofre Lopes, celebrando convênios com a Prefeitura para prestação de serviços de medicina, odontologia e farmácia nos Acampamentos Escolares. E semanalmente, o Prefeito Dialma Maranhão, através do rádio, prestando contas ao povo num testemunho de sua administração transparente tudo, tudo se soma, politicamente, em "De Pé no Chão Também se Aprende a Ler" que liderava uma ampla política de educação e de cultura em Natal. E para não dizerem que não falei de números, ai vão as estatísticas mais gerais: de 1960 a abril de 1964, "De Pé no Chão Também se Aprende a Ler" tem uma matrícula acumulada de mais de 40.000 alunos; seu magistério se constitui de 500 professores leigos qualificados em cursos de emergência do Centro de Formação de Professores; seu quadro de supervisores era de 32 profissionais formados pela Escola Normal e pela Faculdade de Filosofia Ciências e Letras de Natal, sendo o custo-aluno anual menos de dois dólares.

\section{Quais foram os grandes desafios da Campanha "De Pé no Chão Também se Aprende a Ler"?}

Moacyr de Góes: "De Pé no Chão Também se Aprende a Ler," visto numa perspectiva histórica de 43 anos, venceu quatro desafios comuns à escola brasileira. i) não confundiu escola com prédio escolar; ii) qualificou com seus próprios recursos humanos e municipalizou o ensino normal de formação de professores; iii) produziu seus próprios textos educativos face à alienação das cartilhas então existentes no mercado; iv) o acompanhamento técnico-pedagógico se fez na proporção de um supervisor para vinte professores. Sobre esses quatro itens temos a dizer: primeiro, ao aceitar o desafio da "escola de palha," a Campanha "De Pé no Chão Também se Aprende a Ler" terminou chamando a atenção para a recriação da escola. Segundo, quem faz a educação escolar deve estar ciente, criticamente, da proposta que desenvolve. Terceiro, o fato de participar, pelo menos em uma parte, da produção do material pedagógico, foi uma lição quase tardia que aprendemos. "De Pé no Chão Também se Aprende a Ler" já havia resolvido o problema do espaço físico e da qualidade do professor que colocava em sala de aula, mas adotava cartilhas alienadas como bem demonstra o filme do MEC, sobre a nossa Campanha. Foi preciso 
uma reunião do Círculo de Pais e Professores das Rocas para nos abrir os olhos. Sobre o assunto recebemos também grande contribuição de Paulo Freire e da Ação Popular (AP). Aqui, também, caminhando fizemos o caminho... Quarto, os supervisores, os orientadores e coordenadores eram escolhidos por serem mais habilitados e de maior vivência de sala de aula, assim, poderiam assegurar mais êxito à política educacional. Em "De Pé no Chão Também se Aprende a Ler" o acompanhamento do processo de ensino e aprendizagem se fazia na proporção de um supervisor, orientador ou coordenador para vinte profissionais que estavam na sala de aula do Acampamento. $\bigcirc$ treinamento desses quadros era feito em serviço através de reuniões semanais, com o cuidado de estimulá-los a saber ver, ouvir, conversar, demonstrar e aprender também. A relação pessoal era de competência profissional e solidariedade humana e não a de fazer de um saber uma dominação de poder.

\section{A Campanha "De Pé no Chão Também se Aprende a Ler" foi um laboratório de experimento de uma educação escolar pública, gratuita, democrática e de qualidade social?}

Moacyr de Góes: Em apresentação chamada Recife: Cultura e participação, escrito para contextuar a primeira obra de Paulo Freire Educação e atualidade brasileira, tese de concurso para a cadeira de "História e Filosofia da Educação" na Escola de Belas-Artes de Pernambuco (1959), o professor Paulo Rosas, um dos fundadores do Movimento de Cultura Popular (MCP) diz: "De 1960 a 1964, Recife pode ser considerado como um laboratório, onde se desenvolveu um experimento único. $\bigcirc$ fato é que a cidade, naquele período, foi um laboratório. Claro, o experimento não poderia se encaixar nos cânones positivistas. Nem se precisaria disto. Seguiu, enquanto experimento, sem planejamento ortodoxo. Sem definição de objetivos nem de hipóteses. Sem deliberada construção de instrumentos. Sem caracterização de amostra, nem sorteio aleatório, nem controle de variáveis. As mudanças foram acontecendo."Estas palavras sobre o Recife poderiam ser ditas, com todas letras, para Natal. Afinal, é próprio de um movimento popular sem um mínimo de institucionalização e um máximo de criatividade. Nos anos 1970, quando o peso da bota da ditadura foi maior, quando não tínhamos horizontes claros, costumávamos repetir, na resistência, inspirados em Marti: "[...] é caminhando que se faz o caminho." Aplicando o princípio aos anos da Campanha, vamos 
identificar uma mudança entre o contexto 1960-1961 e o ano de 1963, quando "De Pé no Chão Também se Aprende a Ler," apresentou um documento de política educacional ao I Encontro Nacional de Alfabetização e Cultura Popular, realizado no Recife, em setembro. Sua conclusão demonstrava que o caminho estava sendo caminhado. Diz ele: "Há um entrelaçamento dialético entre cultura popular e libertação nacional socialismo e luta antiimperialista. Por conseguinte, embora pareça em princípio paradoxal, a cultura popular tem papel de instrumento de revolução econômico-social, mas, em última instância, a afirmação e vitória desta revolução é que iria possibilitar o surgimento das mais autênticas criações populares, livres das alienações que se processam no plano político e econômico."

\section{A memória da Campanha "De Pé no Chão Também se Aprende a Ler" está sendo discutida e rediscutida criticamente?}

Moacyr de Góes: Quero registrar, também, que nestes 43 anos houve um grande esforço acadêmico em discutir criticamente a educação popular desenvolvida em Natal, gerada pelo movimento popular que se expressou através dos Comitês Nacionalistas que, em 1960, elegeram Dialma Maranhão seu Prefeito. E devo repetir, por uma questão de justiça, que o primeiro intelectual a levar a Campanha "De Pé no Chão Também se Aprende a Ler" para a discussão universitária foi o professor José Willington Germano, por meio de sua dissertação de mestrado, defendida na UNICAMP, editada em 1982, sob o título Lendo e apreendo - A Campanha "De Pé no Chão." De uma forma documentada e crítica, Willington Germano, resgata a engenharia política dos anos 1960, no Rio Grande do Norte, e nesse contexto discute "De Pé no Chão." Assim, vinte e um anos depois, a academia brasileira passava a discutir, oficialmente, a política educacional de Natal para erradicar o analfabetismo nos anos 1960. Dois anos antes, a Editora Civilização Brasileira, como política de resistência à ditadura, editava o meu livro "De Pé no Chão Também se Aprende a Ler - uma escola democrática," dez anos depois reeditado pela Cortez. Durante todos os anos 1970, eu recolhera os cacos que sobraram, isto é, fontes escritas, orais e iconográficas e quando chegou à anistia o texto já estava em mãos de Enio Silveira. No entanto, sei através de notícias e conversas, que, nestes 43 anos, vários textos sobre a administração 
do Prefeito Dialma Maranhão e particularmente sobre "De Pé no Chão" foram produzidos pela UFRN, dentre outras instituições. Vinte e quatro anos depois da fundação da Campanha "De Pé no Chão Também se Aprende a Ler," o editor Jorge Zahar pretendeu documentar, em uma coleção, os anos de chumbo do Brasil e eu fui convidado a escrever sobre educação. Daí surgiu minha parceria com Luís Antônio Cunha e juntos escrevemos $\bigcirc$ Golpe na educação. Este texto de fácil acesso que, entre outros temas, registra "De Pé no Chão Também se Aprende a Ler," parece continuar a ser ferramenta para os estudos acadêmicos uma vez que já está na décima edição. Dois anos antes, Osmar Fávero prestava um bom serviço ao estudo do período publicando Cultura popular educação popular - memória dos anos 1960, no qual organiza os documentos produzidos pelos movimentos populares sobre o referido tema. Também o homem simples do povo guarda sua lembrança como tantas vezes já registrei nas minhas vindas constantes a esta terra. E me contam "causos" de Djalma Maranhão, com a inventividade do mito como em Jorge Amado ou Garcia Marquez. Às vezes, lamentando a destruição da utopia em 1964, a linguagem é melancólica como a do verso de Bandeira: "a vida inteira que poderia ter sido e que não foi." Mas, é bom que falem, que continuem a falar, pois, como diz Hannah Arendit numa frase recolhida por Conceição de Góes para seu livro: "Todas as tristezas podem ser suportadas se você as coloca numa história ou conta uma história a seu respeito."

\section{Anos Depois "De Pé no Chão Também se Aprende a Ler", o Prof. Moacyr de Góes tem alguma autocrítica a fazer das concepções e visões de mundo dos concebedores da Campanha?}

Moacyr de Góes: José Willington Germano, em seu livro Lendo e Aprendendo A Campanha "De Pé no Chão," aponta fragilidades teóricas dos dirigentes da Campanha "De Pé no Chão Também se Aprende a Ler," particularmente as minhas. A sua análise baseia-se, principalmente, em dois discursos meus: minha fala de posse na SME (1960) e outra quando do encerramento da I Praça de Cultura de Natal (1961). Quero dizer que concordo com a avaliação e muito de messianismo pedagógico pode ser extraído de minha visão de mundo de então. $\bigcirc$ viés do nacionalismo da época estava muito apontado para a soberania nacional e os conceitos isebianos da alienação e da transplantação cultural. E faltou a análise da luta de classes. Certo. Reconheço que 
em 1960-1961, formular em discursos de massa, a reivindicação de uma revolução cultural antes que a sociedade tivesse feito sua própria revolução dos meios de produção é, no mínimo, colocar o carro adiante dos bois. E o que eu mais lamento é que poucos de nós, ou quase nenhum de nós - conhecia Gramsci. Então, está aqui minha autocrítica no estilo da melhor linha política e acadêmica. Dou-me conta, também, que as teorias e os conceitos são abstrações elaboradas em torno ou a partir de uma problemática real. Portanto, ao introduzirmos uma metodologia para ensinar a ler, escrever e contar, elaborando nossos próprios textos, formando nossos professores e monitores em acompanhamento permanente, permitindo experimentações, correções e adaptações possíveis, estávamos criando uma nova problemática, situação nova no processo de ensino e aprendizagem, condição para a elaboração de novas teorias. Willington Germano, na obra referida, já havia identificado mudanças de formulações ideológicas entre 1961 e 1963 e apontara, com precisão, a causa delas: a participação da Ação Popular (AP), na SME, em postos de decisão. Confirmo Geniberto Campos, Diretor do Ginásio Municipal, foi um excelente formulador de políticas educacionais e Josemá Azevedo, dirigiu com competência a expansão de "De Pé no Chão Também se Aprende a Ler," para

252 diversos municípios do interior do Rio Grande do Norte. Estas duas lideranças de AP me acompanharam ao Recife, em 1963, quando discutimos com Paulo Freire questões importantes sobre os financiamentos da experiência de Angicos (conhecida como método das 40 horas). Devo dizer que, integrando o colegiado de direção de AP, em Natal, ao lado de Geniberto, Josemá e outros, eu me senti mais respaldado, teórico e politicamente, na coordenação da Campanha "De Pé no Chão Também se Aprende a Ler."

\section{Que ângulos novos podem ser ainda enxergados ou teorizados da Campanha "De Pé no Chão Também se Aprende a Ler"?}

Moacyr de Góes: Gosto de citar o Padre Teillard de Chardin quando ele diz que "o homem é um ser inconcluso." Ao curso de minha vida tenho sentido a veracidade desse juízo. Nesses 43 anos da Campanha "De Pé no Chão Também se Aprende a Ler" é possível que eu tenha me detido varias centenas de vezes para documentar, refletir, escrever, falar, discutir, publicar e difundir a Campanha. $O$ assunto para mim é tão mastigado na memória que só recorro às fontes bibliográficas quando se trata de produzir um documento que requer 
técnicas acadêmicas. Pois bem, vez por outra, ainda estou (re)descobrindo um ângulo novo pelo qual é possível lançar mais luz sobre uma determinada especificidade "De Pé no Chão Também se Aprende a Ler" Relato dois momentos que me parecem muito curioso. O primeiro momento diz respeito à "Associação de Educadores Latino-americanos e do Caribe" quando integrei seu Conselho Consultivo, no Brasil. Foi decidido por volta de 1994, que deveríamos preparar para publicação textos sobre a alfabetização de adultos.

Lancei-me à tarefa e fiz um estudo comparado de três cartilhas: a da Revolução Cubana, a do MCP do Recife e a "De Pé no Chão Também se Aprende a Ler." Esta última havia sido uma adaptação para a realidade potiguar do livro de leitura para adultos do MCP, tarefa desenvolvida por Maria Diva da Salete Lucena e equipe do nosso Centro de Formação de Professores. Chamei o estudo de Cuba-Recife-Natal: ou o sonho de três cartilhas de alfabetização para mudar o mundo. O segundo momento se deu quando fui convocado pelo Centro de Filosofia e Ciências Humanas da Universidade Federal do Rio de Janeiro (UFRJ) para contribuir com os estudos comemorativos ao centenário de Anísio Teixeira. Lancei-me, então, a uma releitura dirigida de Mestre Anísio Teixeira. Repassei sua obra teórica, antes e de depois de 1964, cotejando-a com a formulação da educação escolar do Prefeito Djalma Maranhão. Incrível foi o que encontrei nesse estudo comparado: o essencial das propostas de Anísio Teixeira foi realizado em Natal, entre 1960 e abril de 1964. Integrei uma mesa do Seminário: "Um olhar para o mundo. Contemporaneidade de Anísio Teixeira." Levei para lá meu texto Do pensamento de Anísio Teixeira à prática De Pé no Chão Também se Aprende a Ler." Evidentemente que não dá para reproduzir o texto aqui. Mas, em linhas gerais, impossível não falar das posturas coincidentes de teoria e prática, a saber: a identificação na gestão pública da escola nos anos 1960, "De Pé no Chão Também se Aprende a Ler" é o único Movimento de Educação Popular que flui através de uma Secretaria de Estado; a construção da escola democrática na qual a educação não é um privilégio; o papel dos professores; a educação para o trabalho; a escola recriada em cada cultura; a municipalização; a função do intelectual. Em 1966, na III Conferência Nacional de Educação, na Bahia, falando de seu "Centro Educacional Carneiro Ribeiro," dizia Anísio Teixeira: "Tudo isso se fez com a prata de casa. Não houve para essa experiência nem auxílio nem assistência técnica estrangeira de qualquer natureza." Até parecia que ele estava mandando um recado para os Acordos MEC-USAID, como já ocorrera 
com Dialma Maranhão, em 1963, quando para denunciar a ingerência indébita da Aliança para o Progresso, no Sistema de Educação do Rio Grande do Norte, explicitava o Prefeito que na rede municipal de educação de Natal, a escola brasileira era construída com dinheiro brasileiro. Esses momentos aqui relatados enfatizam a ideia de que sempre se pode encontrar um ângulo novo para estudar. Estudar "De Pé no Chão Também se Aprende a Ler" é um "poço" de redescobertas ou de recriação da Escola Pública, como sonhava Anísio Teixeira.

\section{O que levou o Prefeito Dialma Maranhão, o Secretário de Educação, Moacyr de Góes e colaboradores, a colocarem em prática uma experiência de enorme alcance social e de tremendos desafios políticos? Queriam fazer uma história da educação escolar de fato para todos?}

Moacyr de Góes: Hoje vejo que a Campanha "De Pé no Chão Também se Aprende a Ler" foi um salto no escuro e nós nem sabíamos da altura nem da profundidade dele. $\bigcirc$ entusiasmo, o otimismo, a solidariedade aos pobres, a criatividade, a confiança no futuro, a generosidade, a doação de todos, enfim, todos eles juntos foram alavancas que nos moveram. De minhas conversas com Djalma Maranhão, à época, guardo a lembrança de uma grande preocupação comum: se não cimentarmos a aliança da proposta do movimento popular (Comitês Nacionalistas) com os princípios básicos de uma boa educação escolar, vamos fracassar. Daí a preocupação em equilibrar quantidade e qualidade, cidadania e ganhar a credibilidade da população da cidade. Sem perder o horizonte da universalização do conhecimento, a escola precisaria ser recriada pela cultura local. Foi o que fizemos na Campanha "De Pé no Chão Também se Aprende a Ler."

Entrevista concedida por escrito e complementada em conversa no Rio de Janeiro com a Profa. Marta Maria de Araújo. E-mail | martaujo@uol.com.br. 